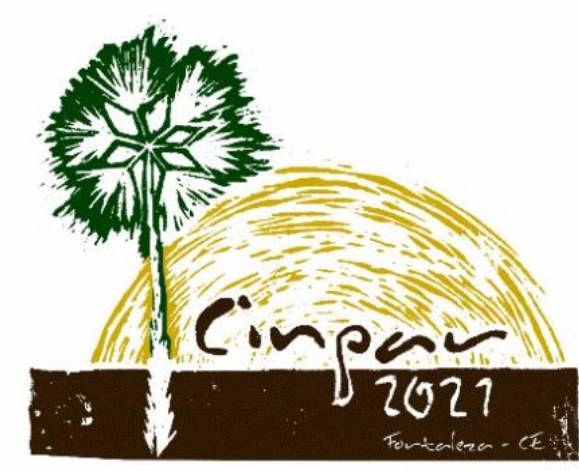

XVII Congresso Internacional sobre Patologia e Reabilitação das Construções

XVII Congreso Internacional sobre Patología y Rehabilitación de las Construcciones

XVII International Conference on Pathology and Constructions Rehabilitation

FORTALEZA (Brasil), 3 a 5 de junho de 2021

https://doi.org/10.4322/CINPAR.2021.130

\title{
Evaluation of degradation agents on facades of buildings located in Brasilia (DF), and their relationship with degradation
}

\author{
Andréia de PAULA ${ }^{1}$ \\ ${ }^{1}$ Universidade de Brasília, Brasília, Brasil, paula_adp@yahoo.com.br
}

\begin{abstract}
Resumo: Os revestimentos de fachada têm como função principal a proteção da envoltória da edificação contra a ação dos agentes externos causadores de degradação. $O$ presente trabalho buscou mensurar a ação dos agentes de degradação sobre a fachada com revestimento em argamassa e relacionar tais agentes com as condições de degradação da fachada de um edifício em Brasília - DF. Para esta análise foi utilizado o software de simulação higrotérmica WUFI ${ }^{\circledast}$ Pro 5.3 , onde foram quantificados os resultados referentes à chuva dirigida, radiação, temperatura e teor de umidade para as fachadas Norte, Sul, Leste e Oeste. A análise da chuva dirigida identificou dois períodos bem distintos, denominados de seco e chuvoso. Em se tratando da radiação a maior parcela de radiação global que a fachada sul recebe durante o ano não advém da incidência direta e sim da difusa. Com relação ao índice de impacto, nota-se que há um incremento significativo do teor de umidade na camada superficial externa composta por argamassa de revestimento, nos primeiros $10 \mathrm{l} / \mathrm{m}^{2}$ de chuva, após esse volume não há alterações significativas. Uma análise sobre o índice de secagem mostrou que não houve diferença significativa do índice de secagem em relação a mudança de absortância, o comportamento foi semelhante para as duas cores analisadas. Os maiores valores de temperatura externa máxima ocorreram no período chuvoso. Na análise da temperatura superficial ficou evidenciado que a absortância influenciou na temperatura e na variação de temperatura na argamassa de fachada. De posse dos resultados de amplitude térmica diária $(\Delta T)$ foi elaborado o Índice de Intensidade da Temperatura (lit), que foi relacionado com os resultados de degradação e quantificados por meio do índice Fator Geral de Danos Adaptado (FGDA). A quantificação dos agentes e relação com a degradação permitiu observar que os agentes climáticos exercem grande influência na degradação das fachadas.
\end{abstract}

Palavras-chave: Degradação, fachadas, FGD

Abstract: Facade coverings have the main function of protecting the building envelope from the action of external agents that cause degradation. The present work sought to measure the action of degradation agents on the Ifacade with mortar coating and to relate these agents to the degradation conditions of the facade of a building in Brasília - DF. For this analysis, the WUFI ${ }^{\circledR}$ Pro 5.3 hygrothermal simulation software was used, where the results related to directed rain, radiation, temperature and moisture content for the North, South, East and West facades were quantified. The analysis of directed rain identified two very distinct periods, called dry and rainy. In the case of radiation, the largest portion of global radiation that the south facade receives during the year is not due to direct incidence, but diffuse. Regarding the impact index, it is noted that there is a significant increase in the moisture content in the external surface layer composed of plastering mortar, in the first $10 \mathrm{l} / \mathrm{m}^{2}$ of rain, after this volume there are no significant changes. An analysis on the drying index showed that there was no significant difference in the drying index in relation to the change in absorbance, the behavior was similar for the two colors analyzed. The highest values of maximum external temperature occurred in the rainy season. In the analysis of the surface temperature it was evidenced that the absorption influenced the temperature and the temperature variation in the facade mortar. With the results of daily thermal amplitude $(\Delta T)$, the Temperature Intensity Index (lit) was elaborated, which was related to the degradation results and quantified by means of the Adapted General Damage Factor (FGDA) index. The quantification of the agents and the relationship with the degradation allowed us to observe that the climatic agents have a great influence on the degradation of the facades. 


\section{Introdução}

A envoltória externa da edificação, é a parcela que mais sofre com os efeitos de degradação oriundos do contato com as condições ambientais e através deles sofre aceleração dos processos de degradação. As fachadas têm um papel importante quanto a estanqueidade, sendo protagonistas na promoção de conforto térmico na medida em que sofrem diretamente trocas de calor com o meio externo. A ABNT NBR $15.575 / 2013$, é um exemplo de marco normativo no que tange às questões de durabilidade. Ela traz em seu escopo a temática da Vida Útil de Projeto, a VUP. Através desse mecanismo busca-se incentivar que projetistas, bem como toda a cadeia se voltem para as questões de previsão de durabilidade e possam conhecer os processos de degradação dos materiais e sistemas que vêm sendo especificados. Entende-se que a durabilidade, passou a partir de 2013 com a promulgação da norma, a ser uma exigência dos usuários. (Zanoni, 2015). Considerando que o Brasil é um país de clima tropical, os sistemas de fachada são submetidos às ações ambientais como altas temperaturas, radiação solar, ação das chuvas e umidade. $O$ estudo dos fatores climáticos e do comportamento dos sistemas diante dessas ações é significativo para a compreensão dos processos de degradação que acometem os edifícios nessa região, visto que as fachadas são continuamente aquecidas pela ação da temperatura e radiação e resfriadas pela ação da chuva e oscilações na temperatura ambiental. (Oliveira et al, 2014). Os elementos de vedação vertical estão submetidos a gradientes de umidade e temperatura sendo que "os fenômenos de transporte de calor e umidade ocorrem simultaneamente e são interdependentes." (Mendes, 1997). Sendo assim, as simulações higrotérmicas são uma importante ferramenta para analisar as diferentes condições de exposição dos edifícios e suas fachadas bem como o comportamento das superfícies mediante diferentes tipos materiais. O presente estudo busca inserir-se nesse contexto através da investigação e quantificação de agentes de degradação ambiental como precipitação, chuva dirigida, umidade, radiação, temperatura e amplitude térmica em relação a sistemas de fachada na cidade de Brasília, por meio de simulação higrotérmica no software Wufi utilizando como base de dados a análise do edifício objeto de estudo e o arquivo climático. A avaliação dos fatores de degradação ambientais mediante simulação de comportamento higrotérmico depende de banco de dados previamente elaborado que apresente características dos materiais a serem simulados, bem como as informações climáticas do local avaliado. Essas informações sobre o clima são avaliadas através de arquivos climáticos que por sua vez são um conjunto de dados obtidos por estações meteorológicas, métodos semi-empíricos e modelos numéricos. Para as simulações computacionais, em geral, é necessário que o arquivo climático seja representativo do local e contenha um ano completo de 365 dias com 8760 dados horários. No caso dos anos bissextos, o dia 29 de fevereiro deve ser descartado.

\section{Metodologia}

O recorte de análise foram as fachadas consideradas em quatro orientações, cujo sistema construtivo foi pintura, argamassa de revestimento e bloco cerâmico. A apresentação da metodologia será determinada a partir da identificação do estudo de caso e suas características, a discriminação dos dados de entrada para a simulação no Wufi, e a descrição dos dados obtidos.

\subsection{Avaliação do estudo de caso e dados de simulação}

O edifício avaliado está localizado na cidade de Brasília (DF) pertencente a zona bioclimática 04, conforme o zoneamento definido pela NBR 15.220/2005. A implantação dá-se na SQN 306, Asa Norte, Bloco C. Trata-se se um edifício com geometria prismática. A edifício foi construído em em concreto armado, dispondo de 7 pavimentos, com altura considerada para fins de análise de 20 metros, cuja fachada apresenta poucos elementos salientes. A idade da edificação é 43 anos.

\subsubsection{Avaliação da absortância}

A coloração é um fator determinante na identificação do coeficiente de absortância. Dorneles (2008), realizou um estudo identificando a absortância solar de superfícies opacas para diversos tipos de pintura. 
Com base nos dados gerados nesta pesquisa, foi avaliada a cor e consequentemente a absortância das fachadas do edifício objeto de estudo.

A fachada apresenta duas cores com diferença significativa, que conforme a comparação com as determinações de Dornelles et al (2008), são branco médio e amarelo escuro. A absortância é significativamente diferente para as duas cores o que levou a decisão de abordar nesse estudo as análises para as quatro orientações de fachada, norte, sul, leste e oeste e para as duas cores observadas. A absortância identificada para a cor amarelo escuro foi de 55,5, e para a cor branco médio foi de 37,5 .

\subsubsection{Análise da incidência solar}

A análise da incidência solar, pode ser realizada através da verificação da implantação do edifício referente as cartas solares que são compiladas para cada cidade. A princípio esta análise prescritiva foi realizada a fim de identificar os pontos de fragilidade em relação ao agente de degradação radiação e posteriormente possibilitar um comparativo com os dados obtidos através da análise por simulação. Considerou-se na avaliação da carta solar o azimute de $80^{\circ}$.

\subsubsection{Simulação higrotérmica através do Wufi}

A simulação higrotérmica no software Wufi foi realizada para o sistema de bloco cerâmico, argamassa de revestimento e pintura. A altura do edifício considerada foi de 20 metros e as simulações foram feitas para as quatro as fachadas nos dois casos de absortância: amarelo escuro com 55,5 e branco médio com 37,1.

O arquivo climático utilizado foi o TMY da base EPW-ANTAC (RORIZ, 2012) que contempla precipitação utilizada para a quantificação de chuva dirigida. A simulação foi realizada no período de 02 anos, 04 de abril de 2017 a 03 de março de 2019. Sendo que o primeiro ano simulado foi descartado, para a análise dos dados.

O FGD (fator geral de danos), foi calculado através do Método de Mensuração da Degradação (MMD). O MMD se aplica as fachadas dos edifícios, sendo baseado em inspeções de campo e mapeamento dos danos. Após o mapeamento dos danos, passou-se a fase de quantificação dos mesmos para posterior análise através da utilização da termografia e da ortogonalização de imagens. Após as análises e tratamento dos dados podese prever a vida útil da fachada. Multiplicando o valor do FGD encontrado pela idade do edifício em análise, obtém-se a curva de degradação para o edifício em estudo. Se a curva de degradação do edifício analisado estiver acima da curva padrão de degradação para a cidade de Brasília significa que a degradação está ocorrendo de forma mais lenta, caso contrário, significa que a degradação está ocorrendo de forma mais acelerada.

A composição do sistema, bem como a espessura das camadas e posicionamento das câmeras de análise podem ser observadas na Figura 1 que ilustra a interface do software de simulação higrotérmica utilizado.

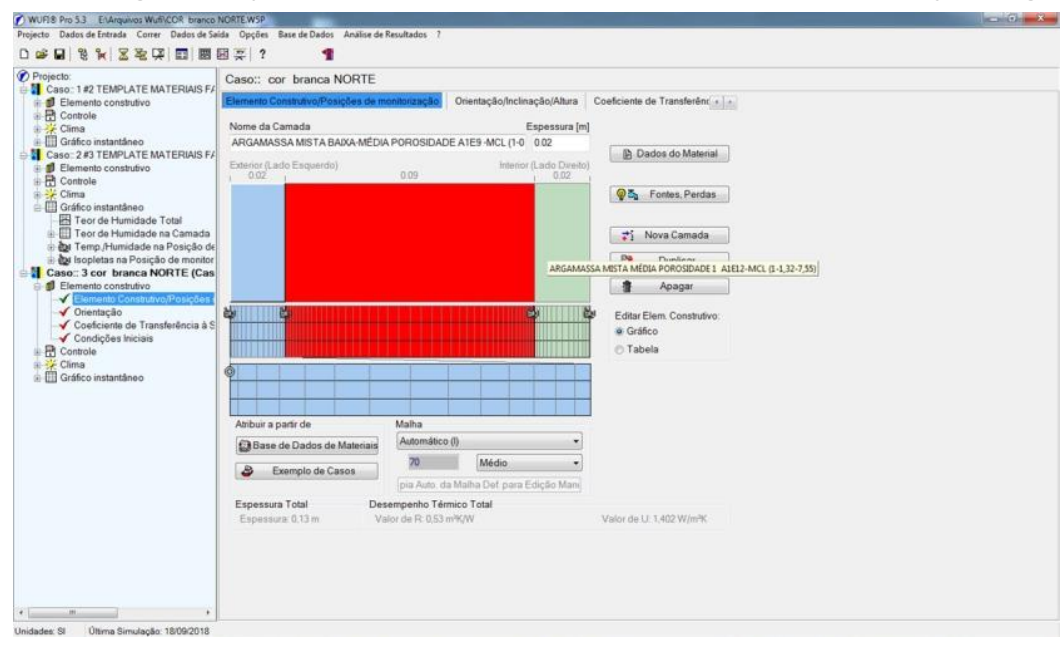

Figura 1 - Interface do Wufi apresentando o sistema construtivo analisado 


\section{Resultados}

\subsection{Avaliação dos Parâmetros}

\subsection{1 - Radiação Solar}

O primeiro item avaliado em relação a radiação solar foi a média de radiação solar global mensal por fachada ao longo do ano climático. Observou-se que nos meses de abril a setembro há uma maior incidência na fachada norte e nos meses de outubro a março ela acontece na fachada leste seguida da fachada oeste. A fachada que menos recebe incidência de radiação ao longo do ano é a sul. Em relação a radiação solar direta nota-se o mesmo comportamento de incidência observado na radiação global. No entanto esta avaliação permite identificar que a maior parcela de radiação global que a fachada sul recebe durante o ano não advém da incidência direta e sim da difusa. Visto que a mesma recebe radiação direta em pequena quantidade e somente nos meses de outubro a fevereiro. A análise do demonstrativo acumulativo de radiação direta mensal demonstrou que os meses de maior quantidade de radiação são junho e janeiro. Em junho têm-se a maior incidência acumulativa do ano e a maior parte se dá na fachada norte sendo o máximo anual, e notase praticamente a ausência de radiação direta na fachada sul. $O$ acumulativo apresenta-se praticamente equivalente para as fachadas leste e oeste, exceto no mês de agosto onde há uma preponderância de incidência na fachada oeste. A fachada sul apresenta o acumulativo zerado de abril a setembro.

\subsection{2 - Chuva Dirigida}

A chuva dirigida foi primeiramente avaliada em relação ao seu quantitativo mensal ao longo do ano. Notouse que nos meses de abril a setembro há um quantitativo menor de chuvas, indo ao encontro do observado para as análises do clima de Brasília, onde os períodos seco e chuvoso são claramente determinados. (Zanoni, 2015). A chuva dirigida é mais incidente na fachada norte nos meses de novembro a abril. Percebeu-se que o período seco coincidiu com o período de maior percentual de radiação direta acumulada durante o ano, sendo que no mês de junho quando ocorre o pico de radiação direta acumulada, não há chuvas. Em relação aos picos de chuva dirigida, apesar da quantidade de chuva ser maior na fachada norte ao longo do período chuvoso, os picos são variados e não se pode observar preponderância em uma determinada fachada. No entanto no período seco os picos são maiores nas fachadas leste e sul.

\subsection{3 - Índice de Impacto}

$\mathrm{Na}$ fachada norte, nota-se que há um incremento significativo do teor de umidade na camada superficial externa composta por argamassa de revestimento, nos primeiros $10 \mathrm{l} / \mathrm{m}^{2}$ de chuva, sendo que após esse volume não há alterações significativas do teor. Na fachada sul, o índice de impacto é mais elevado se comparado a fachada norte e continua a aumentar após os $10 \mathrm{l} / \mathrm{m}^{2}$ de volume de chuvas. A camada intermediária composta por tijolo cerâmico apresenta maior incremento do teor de umidade se comparado a fachada norte. A fachada leste apresenta um comportamento semelhante a fachada sul e a fachada oeste apresenta um comportamento semelhante ao da fachada norte. A anáilise do índice de impacto foi feita com dados diários.

\subsection{4 - Índice de Secagem}

O índice de secagem é um fator que indica a resistência a secagem das camadas que compõe o sistema de revestimento e pode ser associado diretamente com a porosidade do material. Os índices de secagem em todas as fachadas e ambas as cores de análise são observadas no intervalo de $350 \mathrm{l} / \mathrm{m}^{2}$ a $375 \mathrm{l} / \mathrm{m}^{2}$. Não houve diferença significativa do índice de secagem em relação a mudança de absortância, sendo o comportamento semelhante. A fachada com os maiores índices de secagem é a fachada norte. E por fim numa escala menos acentuada a fachada oeste apresenta um comportamento semelhante a fachada norte.

\subsection{5 - Temperatura}


Os maiores valores de temperatura externa máxima ocorreram nos meses de setembro e fevereiro, ambos no período chuvoso. A maior ocorrência de valores máximos de temperatura externa se deu no intervalo de $26^{\circ}$ a $30^{\circ} \mathrm{C}$. A análise realizada em um dia típico identificou que as temperaturas máximas se encontram em sua maior parte no intervalo de $25^{\circ}$ a $30^{\circ}$ e as mínimas de $15^{\circ}$ a $20^{\circ} \mathrm{C}$.

Analisando as médias de temperaturas máximas mensais nas fachadas com coloração branca, tem-se que a orientação oeste apresenta as maiores máximas ao longo do ano exceto nos meses maio, junho, julho e agosto, em que elas ocorrem na fachada sul. Na avaliação referente a cor amarelo escuro, o comportamento é semelhante em relação as máximas, no entanto o intervalo tem temperaturas foi superior. A diferença que pode ser notada se dá principalmente em relação a fachada oeste que apresenta um incremento nas médias de temperaturas máximas significativo aproximando-se do comportamento observado na fachada oeste.

\subsection{6 - Amplitude Térmica}

A amplitude térmica é um importante fator a ser analisado pois através dele pode-se identificar quais fachadas estão mais suscetíveis a ocorrências do fenômeno de choques-térmicos. Para a fachada branco médio, nos meses de abril a agosto a média de amplitude maior se dá na fachada norte, e varia de $15^{\circ} \mathrm{C}$ a $20^{\circ} \mathrm{C}$, nos demais a fachada oeste se destaca, seguida da fachada leste num intervalo de $12^{\circ} \mathrm{C}$ a $16^{\circ} \mathrm{C}$ aproximadamente. No caso da análise para a cor amarelo escuro, o comportamento é semelhante ao descrito para a cor branco médio sendo que o intervalo de valores tem um acréscimo de aproximadamente $5^{\circ} \mathrm{C}$, sendo que para a fachada sul nota-se o intervalo de $18^{\circ}$ a $26^{\circ} \mathrm{C}$ e para a fachada oeste de $15^{\circ}$ a $24^{\circ} \mathrm{C}$. Ao observar os picos de temperaturas mensais nas fachadas, observa-se o comportamento é semelhante ao descrito para as médias de amplitude.

\subsection{7 - Choque térmico}

Para a cor branco médio, observou-se que o choque térmico pleno ocorreu somente na fachada oeste e em maior quantidade no mês de agosto, com um total de 8 eventos. Já na análise realizada para o amarelo escuro nota-se que o fenômeno passa a acontecer em todos os meses do ano e de maneira mais significativa nas fachadas leste e oeste. A maior quantidade de eventos também ocorre no mês de agosto para a fachada oeste, mas com o quantitativo de 25 eventos, o triplo do observado na cor branco médio.

Os eventos de choque térmico atenuado ocorrem com mais frequência em ambas as absortâncias analisadas. Para o branco médio têm-se que a fachada norte apresenta o maior número de eventos nos meses junho e julho com mais de 80 ocorrências, seguida da fachada oeste. Já em relação a cor amarelo escuro os eventos de choque térmico também acontecem em maior número na fachada norte, com quantitativos mais expressivos em abril e agosto, se comparado a fachada sul e com número de eventos máximo de quase o dobro. No período seco a ocorrência se dá em maior parte na fachada leste, ressaltando que as ocorrências passam a se dar também na fachada sul.

\subsection{8 - Perfis de Temperatura}

Os perfis foram elaborados para as 04 fachadas considerando os dias mais críticos do ano para cada fachada em relação a temperatura externa. A elevação da temperatura externa a ponto de superar a temperatura das camadas internas ocorreu entre o intervalo de $9 \mathrm{~h}$ às $20 \mathrm{~h}$ em todas as fachadas.

Em todos os casos a temperatura das camadas 02 (bloco cerâmico) e 03 (argamassa de revestimento interna) se mantiveram relativamente estáveis sem grandes alterações. As alterações significativas de temperatura ocorrem na camada superficial da fachada e na camada de revestimento externo em argamassa.

$\mathrm{Na}$ fachada norte esse aumento ocorreu de forma mais acelerada do que na fachada sul, onde houve um aumento mais lento da temperatura. As fachadas leste e oeste tiveram comportamentos semelhantes e apresentaram uma elevação de temperatura com os picos de temperatura ocorrendo em horários distintos.

\section{2 Índice de Incidência de Temperatura (ITT)}

O IIT foi elaborado com o objetivo de caracterizar à incidência do clima sobre os edifícios, levando em consideração a representação de forma ponderada dos efeitos dos ciclos (frequências) e valores alcançados 
de temperaturas no sistema. Este índice foi elaborado utilizando também os valores de variação de temperatura $\Delta \mathrm{T}$. A escolha do parâmetro variação de temperatura foi baseada na sua capacidade de representar as mudanças devido aos ciclos de variação climática. Para o cálculo do índice, a faixa de variação da amplitude de temperatura foi dividida em quatro intervalos iguais. Para as fachadas analisadas, $\mathrm{o} \Delta \mathrm{T}$ máximo encontrado foi de $29,32^{\circ} \mathrm{C}$ e o mínimo de $13,19^{\circ} \mathrm{C}$. Porém para o cálculo do IIT, foram utilizadas as faixas de temperatura definidas por Nascimento (2016), sendo as faixas: $3,4-11,5^{\circ} \mathrm{C} ; 11,5-19,6^{\circ} \mathrm{C} ; 19,6-$ $27,7^{\circ} \mathrm{C}$ e $27,7-35,8^{\circ} \mathrm{C}$.

Foi feita a quantificação das faixas de $\Delta \mathrm{T}\left({ }^{\circ} \mathrm{C}\right)$ e analisada a frequência de ocorrência de $\Delta \mathrm{T}\left({ }^{\circ} \mathrm{C}\right)$ para cada faixa de temperatura para posterior cálculo do IIT. Multiplicando o $\Delta T$ da Faixa pela frequência de ocorrência e dividindo o resultado por 365 , encontramos o valor de IIT para cada orientação de fachada, levando em consideração às duas cores estudadas. De posse do IIT, para encontrarmos o valor de IIT Total, bastou multiplicar o valor de IIT encontrado por 43 anos (idade do edifício em estudo).

\subsection{Correlação entre o FGD e a umidade}

A amplitude de umidade da camada superficial não apresentou uma relação com o FGD para todas as fachadas. O mesmo ocorreu com o teor de umidade máximo da camada, que também não apresentou relação com o FGD.

\subsection{Correlação entre o Índice de Incidência de Temperatura (ITT) e o Fator Geral de Danos (FGD)}

Com base nos valores de FGD obtidos para as quatro fachadas estudadas elaborou-se o gráfico Figura 2, para as quatro fachadas analisadas nas idades de 10,20,30, 40 e 43 anos, que compara a curva de envelhecimento da cidade de Brasília com a curva de envelhecimento de cada uma das fachadas estudadas, permitindo assim, uma análise da vida útil de cada uma das fachadas, bem como uma avaliação da degradação, permitindo detectar se a fachada em estudo apresenta uma degradação mais ou menos acelerada do que o previsto em projeto.

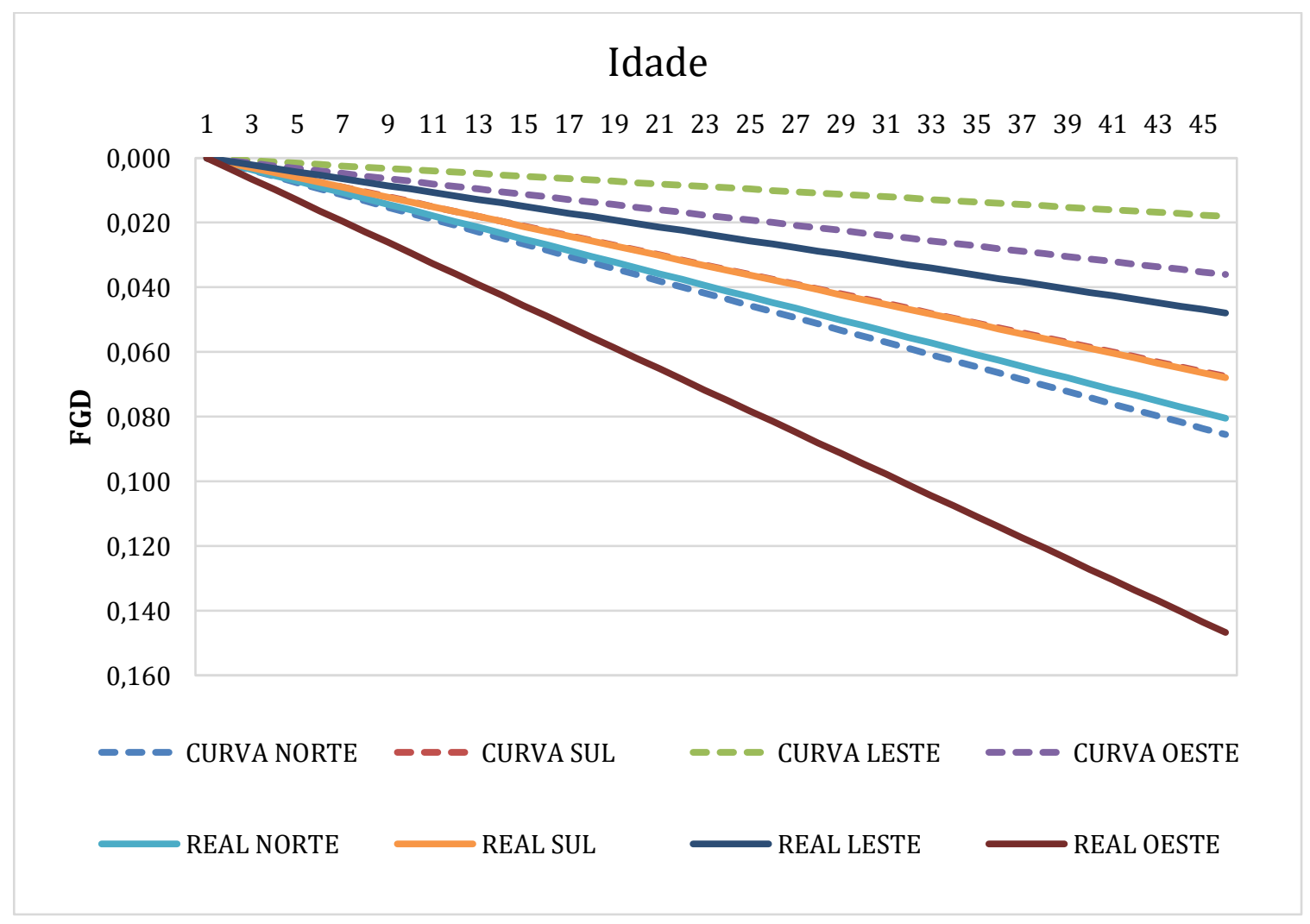

Figura 2: Gráfico do FGD para as quatro fachadas estudadas, nas idades de 10, 20, 30, 40 e 43 anos 
Ao observar a curva de envelhecimento obtida para Brasília e a curva de envelhecimento encontrada para a fachada norte, nota-se que aproximadamente nos primeiros 20 anos de exposição elas são coincidentes, a partir desta idade há uma desassociação não muito sensível, que se acentua na idade atual do edifício que é 43 anos, indicando que a fachada analisada degradou menos que o esperado. Nota-se que a vida útil manteve o desempenho esperado nos primeiros 30 anos. No caso da fachada sul, foi encontrado uma identificação com a curva dose-resposta encontrada para Brasília, inclusive nos períodos mais avançados de degradação. No caso da fachada leste, a degradação foi sensivelmente maior que o esperado conforme a curva doseresposta de Brasília. O distanciamento aumenta com o tempo de exposição aos fatores de degradação. No caso da fachada oeste o comportamento foi semelhante ao da fachada leste, no entanto a vida útil dessa fachada foi a menor, dentre todas as fachadas estudadas.

\subsection{Correlação entre o FGD e a ocorrência de choque térmico pleno e atenuado}

Assim como na correlação com o IIT nota-se que o choque térmico se mostra com maiores valores na fachada oeste das duas cores analisadas, isto pode ser explicado pelo acúmulo de fatores de degradação como a radiação direta e temperaturas superficiais maiores por causa da orientação do edifício.

O choque térmico pleno ocorre somente para a fachada oeste e a frequência de ocorrência é proporcional ao aumento do FGD e o tempo de exposição aos fatores de degradação, ou seja, a idade.

Observou-se também que a ocorrência de eventos de choque térmico atenuado aumenta com a idade para todas as fachadas, no entanto a degradação é maior nas fachadas norte e leste, visto que com menos tempo de vida, elas apresentam maior ocorrência de eventos e maior FGD. Para os fenômenos de choque térmico atenuado a degradação se deu mais intensamente nas fachadas oeste e norte.

\section{Conclusões}

A análise da média de radiação solar global mensal por fachada ao longo do ano climático e a radiação solar direta, evidenciou que nos meses de abril a setembro há uma maior incidência na fachada norte e nos meses de outubro a março ela acontece na fachada leste seguida da fachada oeste, sendo a fachada sul, a que menos recebe incidência de radiação ao longo do ano. Pode-se também constatar que a maior parcela de radiação global que a fachada sul recebe durante o ano não advém da incidência direta e sim da difusa.

Da análise da chuva dirigida, constatou-se que nos meses de abril a setembro há um quantitativo menor de chuvas, indo ao encontro do observado para as análises do clima de Brasília, onde os períodos seco e chuvoso são claramente determinados. O períoso seco coincidiu com o período de maior percentual de radiação direta acumulada durante o ano. A quantidade de chuva dirigida é maior na fachada norte ao longo do período chuvoso. Notou-se que ocorreu um incremento do percentual de umidade na fachada norte quando se analisou a camada superficial externa composta por argamassa de revestimento nos primeiros $10 \mathrm{l} / \mathrm{m}^{2} \mathrm{de}$ chuva. Na fachada sul, o índice de impacto é mais elevado se comparado a fachada norte e continua a aumentar após os $10 \mathrm{l} / \mathrm{m}^{2}$ de volume de chuvas. $O$ índice de sacagem, não apresentou diferença significativa em relação a mudança de absortância, sendo o comportamento semelhante para ambas as cores da fachada. A fachada norte apresentou os maiores índices de secagem. Em se tratando da temperatura, observou-se que os maiores valores de temperatura externa máxima ocorreram nos meses de setembro e fevereiro, ambos no período chuvoso. Analisando as médias de temperaturas máximas mensais nas fachadas com coloração branca e coloração amarelo escuro, tem-se que a orientação oeste apresenta as maiores máximas ao longo do ano, exceto em alguns meses, em que elas ocorrem na fachada sul. Para a fachada branco médio, nos meses de abril a agosto a média de amplitude térmica maior se dá na fachada norte. No caso da análise para a cor amarelo escuro, o comportamento é semelhante ao descrito para a cor branco médio sendo que o intervalo de valores tem um acréscimo de aproximadamente $5^{\circ} \mathrm{C}$. Com relação ao choque térmico pleno, observou-se que para a fachada de cor branco médio ele só ocorreu na fachada oeste com a maior incidência no mês de agosto. Em se tratando da fachada de cor amarelo escuro nota-se que o fenômeno passa a acontecer em todos os meses do ano e de maneira mais significativa nas fachadas leste e oeste, sendo que a maior quantidade de eventos também ocorre no mês de agosto. A absortância não influenciou no choque 
térmico atenuado, pois estes ocorrem com maior frequência em ambas as cores de fachada analisadas. Ocorrendo com maior frequência na fachada norte. Dos perfis de temperatura estudados, pôde-se observar que as alterações significativas de temperatura ocorrem na camada superficial da fachada e na camada de revestimento externo em argamassa. Na fachada norte esse aumento ocorreu de forma mais acelerada e na fachada sul, observou-se um aumento mais lento. A verificação da relação entre a quantificação do índice de incidência de temperatura e a quantidade da degradação se deu através da verificação do Fator Geral de Danos (FGD). Ao avaliar os valores de FGD para as quatro fachadas analisadas nas idades de 10, 20, 30, $40 \mathrm{e}$ 43 anos e comparar com a curva de envelhecimento obtida para a cidade de Brasília, constatou-se que para a fachada norte, nos 20 primeiros anos de exposição, as duas curvas estão praticamente sobrepostas, sendo que a partir dessa idade há uma desassociação não muito sensível, indicando que a fachada analisada degradou menos que o esperado. As curvas para a fachada sul também estão praticamente sobrepostas, inclusive nos períodos mais avançados de degradação. Para a fachadas leste e oeste, a degradação foi maior que o esperado, sendo que o distanciamento das curvas aumenta com o tempo de exposição aos fatores de degradação. Tal fato, pode ser explicado pela relação entre o fator geral de danos e a ocorrência de choque térmico nas fachadas. Notou-se que os maiores valores de choque térmico se deram na fachada oeste para as duas cores analisadas, o que pode ser explicado pelo acúmulo de fatores de degradação como a radiação direta e temperaturas superficiais maiores por causa da orientação do edifício. Prova disso, é que o choque térmico pleno ocorre somente para a fachada oeste. Embora a fachada norte tenha recebido maior incidência de radiação e de chuva dirigida como pode ser verificado nesse estudo, sua degradação ficou dentro do esperado em projeto. Mostrando que estes fatores não foram decisivos para a degradação.

A amplitude de umidade da camada superficial e o teor de umidade máxima da camada, não apresentaram relação com o fator geral de danos (FGD).

\section{Referências Bibliográficas}

DORNELLES, Kellen Almeida at all. Influência das Tintas Imobiliárias Sobre o Desempenho Técnico e Energético das Edificações. Artigo. Campinas, 2008.

NASCIMENTO, Mateus Leoni Martins. Aplicação da Simulação Hidrotérmica na Investigação da Degradação de Fachadas de Edifícios. Tese (Mestrado). Universidade de Brasília. Brasília, 2016.

MENDES, Nathan. Modelos para Previsão da Transferência de Calor e de Umidade em Elementos Porosos de Edificações. Tese (Doutorado). Universidade Federal de Santa Catarina. Florianópolis, 1997.

OLIVEIRA, L. A.; FONTENELLE, J. H.; MITIDIERI FILHO, C. V. Durabilidade de Fachadas: método de ensaio para verificação da resistência à ação de calor e choque térmico. Ambiente Construído, Porto Alegre, v. 14, n. 4, p. 53-67, out./dez. 2014. ISSN 1678-8621 Associação Nacional de Tecnologia do Ambiente Construído.

WUFI Pro 5.3. IBP - Fraunhofer Institute for Building Physics. Holzkirchen, Germany, 2013.

ZANONI, V. A. G. Influência dos Agentes Climáticos de Degradação no Comportamento Higrotérmico de Fachadas em Brasília. Tese (Doutorado). Universidade de Brasília, 2015. 